\title{
Measurement of the specific surface area of snow using infrared reflectance in an integrating sphere at 1310 and $1550 \mathrm{~nm}$
}

\author{
J.-C. Gallet ${ }^{1,2}$, F. Domine ${ }^{1,2}$, C. S. Zender ${ }^{1,3}$, and G. Picard ${ }^{1,2}$ \\ ${ }^{1}$ CNRS-INSU, Laboratoire de Glaciologie et Géophysique de l'Environnement, BP 96, 38402 Saint-Martin d'Hères, France \\ ${ }^{2}$ Université Joseph Fourier, Grenoble I, France \\ ${ }^{3}$ Department of Earth System Science, University of California, Irvine, USA
}

Received: 17 November 2008 - Published in The Cryosphere Discuss.: 21 January 2009

Revised: 26 May 2009 - Accepted: 28 July 2009 - Published: 3 August 2009

\begin{abstract}
Even though the specific surface area (SSA) and the snow area index (SAI) of snow are crucial variables to determine the chemical and climatic impact of the snow cover, few data are available on the subject. We propose here a novel method to measure snow SSA and SAI. It is based on the measurement of the hemispherical infrared reflectance of snow samples using the DUFISSS instrument (DUal Frequency Integrating Sphere for Snow SSA measurement). DUFISSS uses the 1310 or $1550 \mathrm{~nm}$ radiation of laser diodes, an integrating sphere $15 \mathrm{~cm}$ in diameter, and InGaAs photodiodes. For SSA $<60 \mathrm{~m}^{2} \mathrm{~kg}^{-1}$, we use the $1310 \mathrm{~nm}$ radiation, reflectance is between 15 and $50 \%$ and the accuracy of SSA determination is $10 \%$. For SSA $>60 \mathrm{~m}^{2} \mathrm{~kg}^{-1}$, snow is usually of low density (typically 30 to $100 \mathrm{~kg} \mathrm{~m}^{-3}$ ), resulting in insufficient optical depth and $1310 \mathrm{~nm}$ radiation reaches the bottom of the sample, causing artifacts. The $1550 \mathrm{~nm}$ radiation is therefore used for SSA $>60 \mathrm{~m}^{2} \mathrm{~kg}^{-1}$. Reflectance is then in the range 5 to $12 \%$ and the accuracy on SSA is $12 \%$. We propose empirical equations to determine SSA from reflectance at both wavelengths, with that for $1310 \mathrm{~nm}$ taking into account the snow density. DUFISSS has been used to measure the SSA of snow and the SAI of snowpacks in polar and Alpine regions.
\end{abstract}

Correspondence to: F. Domine (florent@lgge.obs.ujf-grenoble.fr)

\section{Introduction}

Snow is a porous medium that strongly impacts the energy budget of the Earth (Warren, 1982; Hall, 2004) and the chemistry of the lower troposphere (Domine and Shepson, 2002; Grannas et al., 2007). An important physical property of snow that contributes to these impacts is its specific surface area (SSA). Snow SSA is defined as the surface area per unit mass (Legagneux et al., 2002), i.e. SSA $=S / M=S / \rho_{\text {ice }} V$, where $S$ is the surface area of a given mass of snow particles, $M$ its mass, $V$ is the volume of the snow particles, and $\rho_{\text {ice }}$ is the density of ice $\left(917 \mathrm{~kg} \mathrm{~m}^{-3}\right.$ at $\left.0^{\circ} \mathrm{C}\right)$. SSA values range typically from $2 \mathrm{~m}^{2} \mathrm{~kg}^{-1}$ for melt-freeze layers to $156 \mathrm{~m}^{2} \mathrm{~kg}^{-1}$ for fresh dendritic snow (Domine et al., 2007a).

Light scattering by snow is determined by the size of the snow grains. Grenfell and Warren (1999) showed that the hemispherical reflectance of non-spherical particles could be well represented by a collection of independent spheres having the same $S / V$ ratio as the particles. In this case, the important variable to calculate scattering is the diameter of the spheres, $d_{\text {eff }}$, also called the effective grain size, which is simply related to SSA by:

$\mathrm{SSA}=6 / \rho_{\text {ice }} d_{\text {eff }}$

This demonstrates that SSA is a crucial variable to model snow optics, and therefore the energy budget of snowcovered surfaces. For example, using the DISORT radiative transfer model of Stamnes et al. (1988), we calculated light transmission through the troposphere and in the snowpack, and found that a reduction in SSA of snow from 32 to $16 \mathrm{~m}^{2} \mathrm{~kg}^{-1}$ at the summer solstice at noon, $65^{\circ} \mathrm{N}$, causes an instantaneous forcing of $22 \mathrm{~W} \mathrm{~m}^{-2}$ at the tropopause, increasing column solar absorption by about $6.5 \%$.

Published by Copernicus Publications on behalf of the European Geosciences Union. 
Because of its porous nature, the snowpack adsorbs large amounts of volatile and semi-volatile chemical species. In particular the uptake of persistent organic pollutants (POPs) by the snowpack from the atmosphere has generated considerable interest (Daly and Wania, 2004; Herbert et al., 2005; Domine et al., 2007b; Burniston et al., 2007). If the surface coverage of a POP adsorbed on the surface of snow crystals remains significantly less than a monolayer, its concentration in snow, $[\mathrm{POP}]_{\text {snow }}$, can be expressed as a function of snow $\mathrm{SSA}$, of the partial pressure of the POP, $P_{\mathrm{POP}}$, and of temperature $T$, according to Domine et al. (2007b):

$[\mathrm{POP}]_{\mathrm{snow}}=P_{\mathrm{POP}} \times \mathrm{SSA} / H_{\mathrm{POP}}(T)$

where $H_{\mathrm{POP}}(T)$ is the surface Henry's law constant at the snow temperature, expressed in $\mathrm{Pa} \mathrm{m}^{2} \mathrm{~mol}^{-1}$, while $[\mathrm{POP}]_{\text {snow }}$ is in $\mathrm{mol} \mathrm{kg}^{-1}$. The knowledge of SSA is therefore essential to quantify POP concentrations in snow.

The chemical impact of snow is not limited to the adsorption of species. Photochemical reactions also take place in snow. The photolysis of the nitrate ion in snow, resulting in the emission of $\mathrm{NO}$ and $\mathrm{NO}_{2}$ to the atmosphere, has been the subject of numerous studies (Honrath et al., 1999; Jones et al., 2001; Beine et al., 2002). If it is assumed that nitrate ions are adsorbed on the surface of snow particles, a subject of debate (Beine et al., 2006; Jacobi and Hilker, 2007; Grannas et al., 2007) then the rate of nitrate photolysis also depends on snow SSA, as detailed in Domine et al. (2008).

Despite the importance of snow for both the energy budget of the Earth, and therefore climate, and atmospheric chemistry, and despite the fact that knowing snow SSA is crucial to evaluate quantitatively both aspects, very few data are available on snow SSA. Furthermore, snow SSA changes with time because of snow metamorphism (Flanner and Zender, 2006; Taillandier et al., 2007), but many aspects of its rate of change are not elucidated. This is because up to recently, a rapid and accurate method to measure snow SSA was lacking. This has impeded both the measurement of snow SSA in studies motivated by climate and chemistry issues, and the study of the rate of change of snow SSA in the field and during cold room experiments.

Snow grain size has long been used as a substitute for SSA (Gow, 1969), but given the variety of grain shapes, from dendritic to rounded to hollow, the definition of grain size is ambiguous and observer-dependent (Aoki et al., 2000). With the example of hollow depth hoar crystals, Taillandier et al. (2007) have shown that effective grain size deduced from SSA (Eq. 1) could differ by as much as a factor of 6 from intuitive grain size, which demonstrates that using grain size data can lead to large errors when SSA is needed.

Most published SSA measurements to date have been obtained using methane adsorption at $77 \mathrm{~K}$ (Legagneux et al., 2002; Domine et al., 2007a). Briefly, snow placed in a vacuum container is immersed in liquid nitrogen and the adsorption isotherm of methane on snow is measured, allow- ing the determination of snow SSA. While this method is reliable and accurate, with a reproducibility of $6 \%$, obtaining one value takes three hours and requires liquid nitrogen, a problem in field studies. Another method is stereology (Narita, 1971). Briefly, a snow block is filled with a waterinsoluble liquid that freezes at $T<0^{\circ} \mathrm{C}$ to harden it. Polishing the sample produces serial sections (Perla et al., 1986) that are photographed. The images are then analyzed (Davis et al., 1987) to yield a SSA value after about four hours of work. This method is also well established, but does not work well for fresh snow with high SSA, which cannot be manipulated easily. The smaller structures are easily perturbed by the liquid and by microtoming, and are often unresolved by optical photography. Lastly, X-ray tomography can also produce SSA values (Flin et al., 2003; Kerbrat et al., 2008; Kaempfer and Schneebeli, 2007) but this is not easy to use in the field and the resolution is currently insufficient if SSA $>70 \mathrm{~m}^{2} \mathrm{~kg}^{-1}$ (Kerbrat et al., 2008), a value frequently exceeded in fresh snow.

Theory predicts that the spectral and hemispherical reflectance of snow, $R_{S}$, (i.e. spectral albedo), depends on snow grain size and therefore on snow SSA (Warren, 1982; Grenfell and Warren, 1999). By using the term "hemispherical reflectance", we refer to the terminology recommended by Schaepman-Strub et al. (2006). Here hemispherical reflectance therefore means reflectance integrated over $2 \pi$ steradians, regardless of the geometry of the incident illumination. By measuring simultaneously the biconical reflectance at several wavelengths and the SSA of snow samples, Domine et al. (2006) have verified experimentally that in the short wave infrared (SWIR, 1300 to $3000 \mathrm{~nm}$ ), most variations in snow directional reflectance could be explained by variations in snow SSA, in good agreement with theory. Theory also predicts that grain shape affects hemispherical reflectance (Kokhanovsky, 2006; Picard et al., 2009) but this appeared to be a second order effect in the study of Domine et al. (2006). Those authors also showed plots of biconical reflectance versus SSA for several wavelengths between 1310 and $2260 \mathrm{~nm}$, and suggested that reflectance measurements in that range could be used for SSA determination. Matzl and Schneebeli (2006) used near infrared (NIR) reflectance around $900 \mathrm{~nm}$ to determine SSA vertical profiles in a snow pit with a camera, the SSA- $R_{S}$ calibration being done with stereological measurements. The interest of that method is that it yields vertical SSA profiles rapidly. Painter et al. (2007a) also designed an optical system to rapidly measure snow reflectance around the absorption line at $1030 \mathrm{~nm}$, from which they deduced effective grain size, using the modeling approach of Nolin and Dozier (2000).

Both these latter techniques clearly have enormous potential for stratigraphic studies, but they can be improved by operating at longer wavelength. Reflectance is indeed less dependent on SSA in the NIR than in the SWIR. Figure 1a shows the bihemispherical reflectance of semi-infinite snow layers for four wavelengths: 900, 1030, 1310 and $1550 \mathrm{~nm}$. 
Calculations were performed using DISORT under diffuse light conditions. The SSA-reflectance relationship is highly wavelength-dependent and Fig. 1a shows that a given change in SSA will produce a smaller change in albedo at $900 \mathrm{~nm}$ than at longer wavelength. This is even more obvious in Fig. 1b, where the derivative of the curve in Fig. 1a is plotted as a function of SSA. A given error in measured reflectance translates into a larger error on SSA at $900 \mathrm{~nm}$ than at $1030 \mathrm{~nm}$ and at $1310 \mathrm{~nm}$. Figure $1 \mathrm{~b}$ shows that for a given precision in reflectance measurement, deriving SSA from reflectance will be about twice as accurate at $1030 \mathrm{~nm}$ than at $900 \mathrm{~nm}$, and three times more accurate at $1310 \mathrm{~nm}$. Working at $1550 \mathrm{~nm}$ further improves precision, but only for snows of high SSAs.

Another advantage to work in the SWIR is that ice absorption is greater (Warren and Brandt, 2008), so that the effect of absorbing impurities such as mineral dust and soot decreases as wavelength is increased for values 900, 1030, $1310,1550 \mathrm{~nm}$. For example, we calculate with DISORT that adding $500 \mathrm{ppb}$ of soot particles $(100 \mathrm{~nm}$ in diameter, density $1800 \mathrm{~kg} \mathrm{~m}^{-3}$ and of optical properties $1.73077+i 0.612288$ ) to snow of SSA $=30 \mathrm{~m}^{2} \mathrm{~kg}^{-1}$ changes its bihemispherical reflectance from 0.850 to 0.827 at $900 \mathrm{~nm}$, from 0.701 to 0.693 at $1030 \mathrm{~nm}$, from 0.483 to 0.481 at $1310 \mathrm{~nm}$ and remained unchanged at 0.0475 at $1550 \mathrm{~nm}$. By working at 1310 or $1550 \mathrm{~nm}$, we are therefore unaffected by any likely amount of impurities in snow. Indeed, soot concentrations in snow only rarely exceed $500 \mathrm{ppb}$ (Flanner et al., 2007). Other impurities such as soil dust can at times reach greater amounts, but these are less absorbing than soot, and even concentrations of several ppm have a negligible effect of snow reflectance beyond $1000 \mathrm{~nm}$ (Painter et al., 2007b).

Figure 1 also shows that the accuracy decreases at higher SSA. For studies that focus on monitoring fresh snow SSA, it is therefore particularly useful to work at long wavelength. Moreover, since fresh snow SSA evolves rapidly (Cabanes et al., 2002 and 2003; Taillandier et al., 2007), this is where the exchange of energy and adsorbed species with the atmosphere will change the most rapidly, and there is therefore an enhanced need for an accurate determination of high snow SSA values.

Since snow is not a lambertian reflector, the reflectances measured in many previous studies are not directly comparable with the hemispherical reflectance $R_{s}$. Domine et al. (2006) measured biconical reflectance at a single configuration. The illumination came from the sun with a high solar zenith angle and nadir viewing. Painter et al. (2007a) also measured biconical reflectances, with the source and the receiver fixed at $23^{\circ}$ and $35^{\circ}$ zenith angles respectively. In the photography technique of Matzl and Schneebeli (2006), the viewing angle was normal to the wall but the illumination came from the sun and clouds and was diffused by a cloth laid over the snowpit and by the 4 faces of the snowpits. The camera measured hemispherical-conical reflectances if the illumination was perfectly diffuse but in practice the illumina-
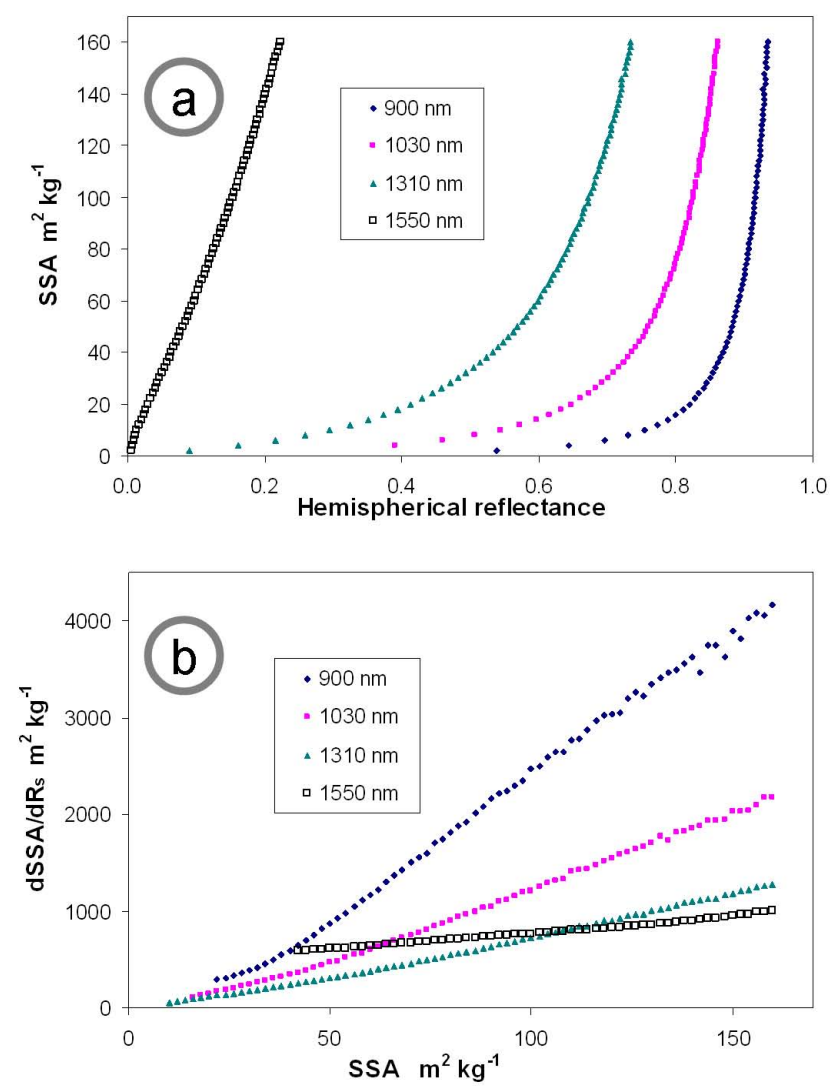

Fig. 1. (a) Relationship between snow specific surface area and bihemispherical reflectance, at four IR wavelengths, calculated with DISORT. (b) Sensitivity of the SSA determination to errors in bihemispherical reflectance at those wavelengths. For a given change in bihemispherical reflectance $d R_{S}$, the change in SSA, dSSA, is greater at $1030 \mathrm{~nm}$ than at $1310 \mathrm{~nm}$, and even greater at $900 \mathrm{~nm}$. For snow of SSA $>110 \mathrm{~m}^{2} \mathrm{~kg}^{-1}$, the lowest sensitivity is obtained at $1550 \mathrm{~nm}$.

tion was dominantly downward and possibly heterogeneous (Matzl and Schneebeli, 2006).

These different optical configurations make intercomparisons between the various systems used difficult at best. Moreover, each system requires its own calibration between reflectance and SSA. Furthermore, the non-lambertian character of snow and its complex bi-directional reflection distribution function (BRDF, Grenfell et al., 1994) imply that biconical reflectance may strongly depend on grain shape. Measuring the hemispherical instead of the biconical reflectance is recommended to measure SSA accurately because hemispherical reflectance is better related to the effective diameter (equivalent to the SSA for optical purposes) than the biconical reflectance (Grenfell and Warren, 1999) and it is less affected by grain shape. The scaled integral approach of Nolin and Dozier (1999) used by Painter et al. (2007a) is also probably less sensitive to grain shape than single band methods but it requires a spectrometer. In any 


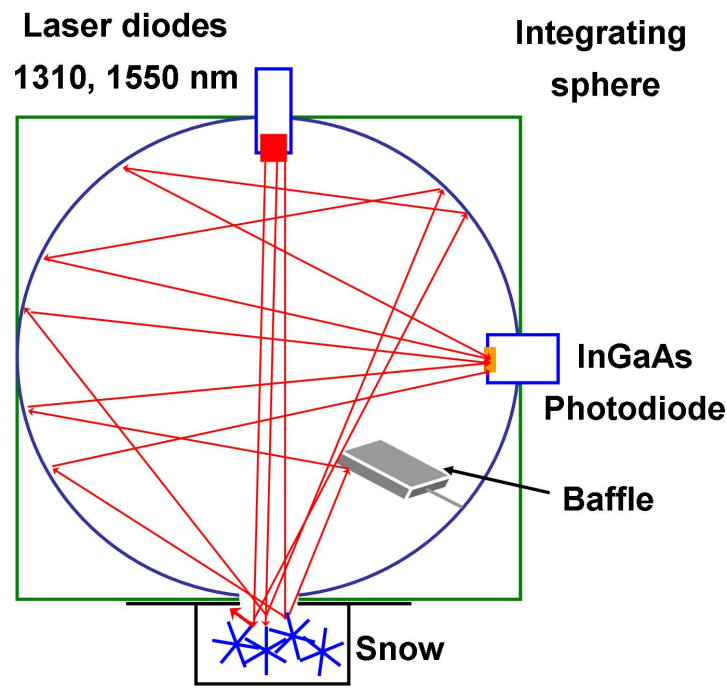

Fig. 2. Schematic of the DUFISSS integrating sphere and components.

case, a stable and reproducible illumination is also important for the reproducibility of measurements, which excludes the sun as the illumination source.

We report here the development of a novel optical system (DUFISSS : DUal Frequency Integrating Sphere for Snow SSA measurements) to measure the hemispherical reflectance of snow samples at 1310 and $1550 \mathrm{~nm}$, the shorter wavelength being optimal for SSA $<60 \mathrm{~m}^{2} \mathrm{~kg}^{-1}$ while the longer one is more efficient for SSA $>60 \mathrm{~m}^{2} \mathrm{~kg}^{-1}$. This new optical system allows one SSA value to be determined in the field in about one minute, and it successfully operates outdoors in polar conditions.

\section{Experimental apparatus}

The system used is shown in Fig. 2. Its main component is a $15 \mathrm{~cm}$ inner diameter (i.d.) integration sphere from Sphere Optics made of Zenith ${ }^{\circledR}$, a polymer with a nominal reflectance near 0.985 in the SWIR. The snow sample is placed in a black sample holder $63 \mathrm{~mm}$ i.d. and 13 or $25 \mathrm{~mm}$ deep. The opening in the sphere towards the snow sample is $38 \mathrm{~mm}$ in diameter. The snow is illuminated directly by the collimated beam from a laser diode at 1310 or $1550 \mathrm{~nm}$ (both supplied by Mitsubishi, and of nominal power $6 \mathrm{~mW}$ ). The beam diameter is about $10 \mathrm{~mm}$ at $1310 \mathrm{~nm}$, as determined using an IR visualization card. As reported in more detail in Sect. 3, there is a detectable flux of photons that directly hit the sphere, so that the actual beam diameter is $>38 \mathrm{~mm}$, even though it is more intense near the center. At $1550 \mathrm{~nm}$, we initially used a beam diameter of $4 \mathrm{~mm}$, later increased to $8 \mathrm{~mm}$. The beam diameter chosen is a compromise between illuminating a representative area and minimizing the numbers of photons hitting directly the sphere. The out-

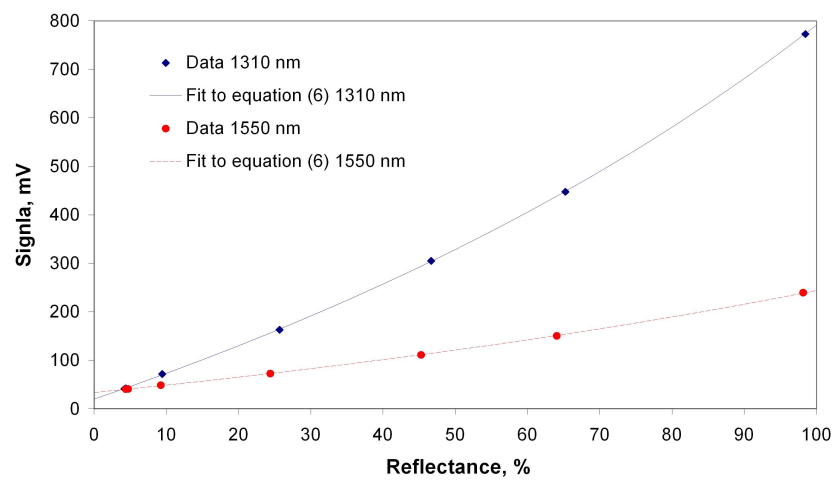

Fig. 3. Calibration curves used to determine snow hemispherical reflectance from the photodiode signals. Graphite-doped Zenith ${ }^{\circledR}$ reflectance standards were used. The curves are not linear because of the reillumination of the standards by their reflected light. The fit to the points was made using Eq. (6), where $\dot{f}=0.962$ at $1310 \mathrm{~nm}$ and $\dot{f}=0.807$ at $1550 \mathrm{~nm}$.

side of the sphere in contact with the snow (Fig. 2) is black, with a reflectance of $3 \%$ in the SWIR. Light reflected by the snow is collected by an InGaAs photodiode, whose current is converted to voltage and amplified before measurement by a high precision voltmeter. Reflectance standards made of graphite-doped Zenith ${ }^{\circledR}$, calibrated by Sphere Optics, are used to determined the reflectance from the photodiode signal. The calibration curve of the photodiode signal is shown in Fig. 3. It is not linear because the sample is re-illuminated by multiple scattering between the sample and the sphere inner surface. The equation used to fit the calibration curve is described in more detail in Sect. 3. Calibration of the reflectance signal to determine SSA was done by measuring successively the snow reflectance, its SSA using methane adsorption, and its reflectance again to detect any change in SSA caused by manipulating the sample.

As mentioned above, crystal shape also affects hemispherical reflectance. Picard et al. (2008) modeled the reflectance of snow crystals of different model shapes (spheres, cubes, cylinders, etc.) using a ray-tracing method at $1310 \mathrm{~nm}$ and observed that for a given SSA, hemispherical reflectance could vary within $\pm 25 \%$ by changing the crystal shape. This contrasts with the experimental data of Domine et al. (2006) who however studied only 12 samples. To further investigate this crucial issue, the snow samples that we used in the SSAreflectance calibration therefore had a wide range of shapes and included highly faceted depth hoar, rounded grains, needles and fresh dendrites.

Two aspects of the reproducibility of our reflectance measurements were determined. The first one was the reproducibility of the measurement of a given snow sample placed in a given sample holder. This was done by placing the sample under the sphere, then removing it and replacing it after a random rotation about a vertical axis. Relative variations 
of reflectance were within $0.3 \%$ at $1310 \mathrm{~nm}$ and $1.5 \%$ at $1550 \mathrm{~nm}$. The second one was to fill the sample holder with snow from one layer sampled in the field in a large container, homogeneized by mixing, and taken to our cold room. The sample-holder container was then emptied and refilled with new snow from the same container. Heterogeneities in the snow layer as well as variations in the way snow was manipulated may then cause signal variations. In that second case, relative variations were within $1 \%$ at $1310 \mathrm{~nm}$ and $2 \%$ at $1550 \mathrm{~nm}$, showing that our reflectance measurements are highly reproducible.

The actual volume of the snow sample probed by the IR beams must be evaluated. The effective beam diameter is uncertain, but we estimate it at $25 \mathrm{~mm}$ at $1310 \mathrm{~nm}$. For snow of $\mathrm{SSA}=35 \mathrm{~m}^{2} \mathrm{~kg}^{-1}$ and density $=200 \mathrm{~kg} \mathrm{~m}^{-3}$, the snow thickness needed to obtain $99 \%$ of the reflectance at infinite thickness is $1.1 \mathrm{~cm}$ at $1310 \mathrm{~nm}$, so that the effective sample volume is estimated to be $5.4 \mathrm{~cm}^{3}$.

At $1550 \mathrm{~nm}$, we estimate the effective beam diameter to be $20 \mathrm{~mm}$. This longer wavelength was used to measure high-SSA snow, so we calculate that for snow of $\mathrm{SSA}=100 \mathrm{~m}^{2} \mathrm{~kg}^{-1}$ and density $=50 \mathrm{~kg} \mathrm{~m}^{-3}$, the snow thickness needed to obtain $99 \%$ of the reflectance at infinite thickness is now $4.2 \mathrm{~mm}$. The effective sample volume is then $1.3 \mathrm{~cm}^{3}$.

As a comparison, the typical snow volume used to measure SSA using methane adsorption is $50 \mathrm{~cm}^{3}$. These three numbers are significantly greater than the minimal snow volumes correctly representing bulk snow properties, and which are always less than $0.1 \mathrm{~cm}^{3}$ for seasonal snow (Coleou et al., 2001).

Given that reflectance measurements are sensitive to the surface state of the sample, we devised a sampling procedure that minimized perturbation. A stainless steel cylinder $63 \mathrm{~mm}$ i.d. (the same as the DUFISSS sample holder) equiped with a piston was used to sample a snow cylinder $30 \mathrm{~mm}$-high, as shown in Fig. 4. A sharp stainless steel spatula is then used to cut a perfectly flat surface at the base of the core while it is still inside the sampling cylinder. The snow core is then pushed into the DUFISSS sample holder, typically $25 \mathrm{~mm}$ deep. The $5 \mathrm{~mm}$ that stick out of the sample holder are then shaved off with the sharp spatula, producing a flat and smooth surface. The only perturbation done to the snow is therefore cutting a flat face with a spatula. With our technique, the face is measured within seconds of cutting, so that any perturbation caused by exposition to warm air is minimized. This temperature aspect is crucial to study fresh snow having high SSA or any snow when the air temperature is near $0^{\circ} \mathrm{C}$, as the presence of liquid water will of course reduce the accuracy of our method in a manner that still needs to be quantified.

Difficulties to obtain a perfect surface were encountered in about $20 \%$ of the cases, which required slight modifications to the protocol, on a case by case basis. It is useful, however, to detail the procedure for hard windpacks. In that case, shav-

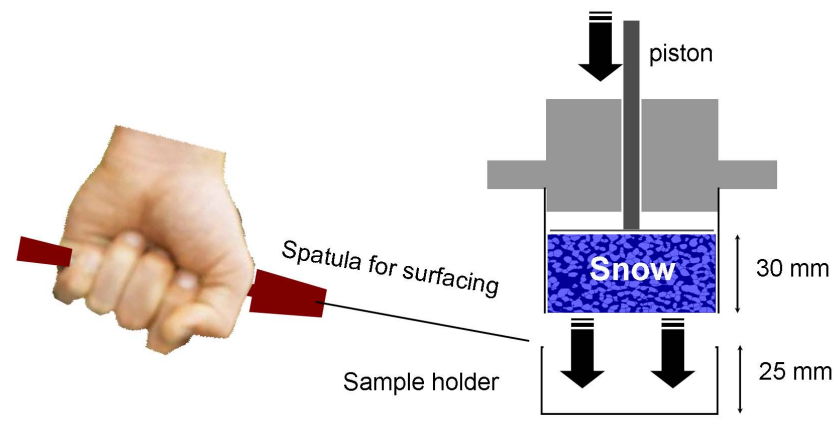

Fig. 4. Sampling device. A cylindrical snow core $30 \mathrm{~mm}$ thick having the exact diameter of the sample holder is taken. The core is pushed into the $25 \mathrm{~mm}$ deep sample holder with a piston. The extra $5 \mathrm{~mm}$ are shaved of with a sharp spatula, providing a fresh surface.

ing off the extra $5 \mathrm{~mm}$ generated small particles that could cause a relative increase in reflectance of $5 \%$. The shaving was then done placing the sample holder vertically and the surface was brushed gently to remove loose small particles. For large depth hoar crystals, it was best to average several samples, as sometimes only a few crystals were probed by the beam. The $1550 \mathrm{~nm}$ wavelength was only used for fresh snow, whose grains were only loosely bonded, so that no detectable effect of sampling was seen despite the short light penetration depth.

The SSA-reflectance calibration data at $1310 \mathrm{~nm}$ is shown in Fig. 5. While for SSA $<66 \mathrm{~m}^{2} \mathrm{~kg}^{-1}$, the data show the expected trend of Fig. 1, we see that for SSA $>66 \mathrm{~m}^{2} \mathrm{~kg}^{-1}$, reflectance values show a lot of scatter and are much lower than expected from an extrapolation of the data at lower SSA: the maximum reflectance is $56.2 \%$, obtained for a SSA of $131.3 \mathrm{~m}^{2} \mathrm{~kg}^{-1}$, and that value is barely higher than $54.4 \%$, obtained for a sample of SSA $65.3 \mathrm{~m}^{2} \mathrm{~kg}^{-1}$. Since all these snows with high SSAs also had a low density, we realized that the geometry of our system could produce artifacts of two kinds, shown in Fig. 6:

- The penetration depth of light can become sufficient in low-density snow so that a significant amount of light reaches the bottom of the black sample holder, where it is absorbed. The optical depth of the snow sample is then insufficient to consider the medium semi-infinite. Hence, the hemispherical reflectance measured by DUFISSS is less than that of a semi-infinite sample (infinite optical depth) having the same SSA. This results in practice in an apparent dependence on snow density (hereafter: density artifact) that prevents SSA determination. Initially, we used a $13 \mathrm{~mm}$-deep sample holder subsequently replaced with a $25 \mathrm{~mm}$-deep one to reduce this artifact. 


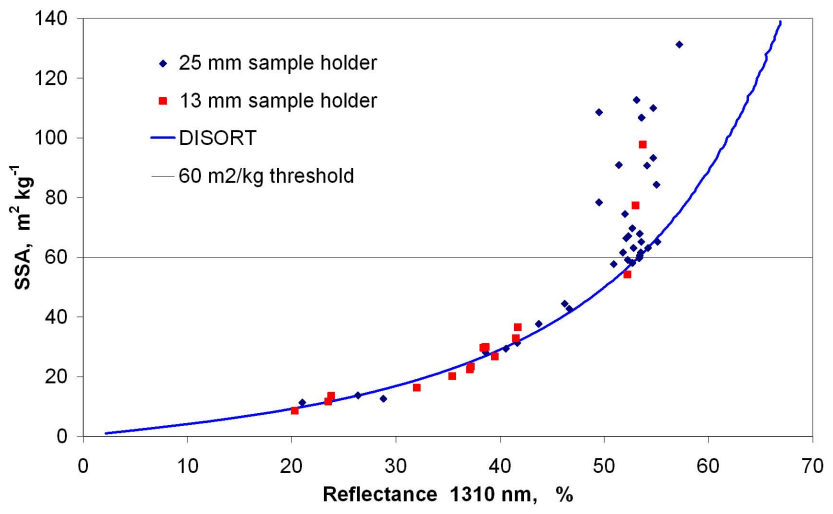

Fig. 5. Calibration curve to determine snow specific surface area from hemispherical reflectance at $1310 \mathrm{~nm}$ measured with the integration sphere. Specific surface area was measured by $\mathrm{CH}_{4}$ adsorption at $77 \mathrm{~K}$. Hemispherical reflectance was obtained with snow samples contained either in a 13 or a $25 \mathrm{~mm}$ deep sample holder. Reflectance was also calculated using the DISORT model, for $25 \mathrm{~mm}$ thick snow samples of density $400 \mathrm{~kg} \mathrm{~m}^{-3}$, with $\omega=0.972$ and $\dot{f}=0.95$, over a surface with $6 \%$ reflectance. For snow with SSA above $66 \mathrm{~m}^{2} \mathrm{~kg}^{-1}$, the scatter and deviation from DISORT calculations are caused by the artifacts detailed in Fig. 6 . The line at $\mathrm{SSA}=60 \mathrm{~m}^{2} \mathrm{~kg}^{-1}$ indicates that above that line, snow usually has a low density and the use of this calibration may lead to large errors. Below $\mathrm{SSA}=1 \mathrm{~m}^{2} \mathrm{~kg}^{-1}$, Mie theory breaks down and calculations are not possible.

- Even if light does not reach the base of the sample holder, light scattered by crystals at a depth $\mathrm{z}$ below the snow surface will have an effective solid angle where reflected light can escape from the cylindrical sample holder that is lower than for a snow crystal located near the surface, where the effective solid angle is in principle $2 \pi$ steradians. This creates an artifact (hereafter: geometric artifact) because 1) the reflectance standards used for the calibration are unaffected by light penetration whereas snow is affected and 2) it results in a slight under-estimation of the reflectance that depends on the optical depth, i.e. the snow density in our case.

Quantifying these effects and correcting them to obtain a calibration curve that would be simple to use required modeling, detailed in Sect. 3. Another option that we pursued after becoming aware of these artifacts was to use a wavelength with a reduced penetration depth. Given commercially available diode lasers, we selected $1550 \mathrm{~nm}$, and the relevant results are detailed in Sect. 4.

\section{Reflectance modeling at $1310 \mathrm{~nm}$}

Our first modeling approach used the DISORT code of Stamnes et al. (1988) in conjunction with snow grain optical properties from Mie theory. This method approximates snow crystals as disconnected spheres and models the reflection of
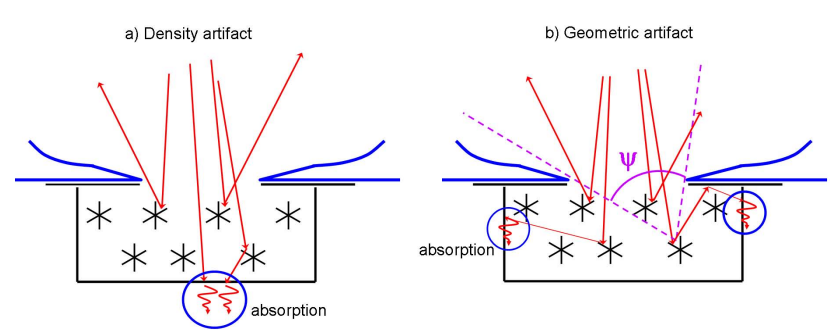

Fig. 6. Two artifacts detected in our system that lower snow reflectance. (a) in low density snow, light penetrates sufficiently deep in the snow that it can reach the bottom of the sample holder, where it is absorbed. (b) light scattered by reflectors below the surface has a reduced probability of escaping, because its field of view is limited by angle $\psi$.

diffuse and directional light by a discrete number of snow layers of finite thickness but infinite in the horizontal direction. To compare our modeling approach to DUFISSS, we used nadir incoming radiation and worked in terms of fluxes. To compute hemispherical reflectance with DISORT, we use 4 computational polar angles (i.e. streams) as recommended in the documentation.

To reduce biases due to discretization and resonance effects (e.g. Zender and Talamantes, 2006), we represent snow crystals as a log-normal distribution of spheres. The reflectance depends slightly on the exact distribution chosen. Since DISORT models disconnected spheres and not real snow, perfect agreement between calculations and experiments is not expected. To optimize the agreement, we chose to adjust the size distribution and the ice optical constants. In all cases we used a log-normal distribution with $\sigma=1.6$, as observed in Antarctica by Grenfell and Warren (1999), and which resolves all sizes between 0.2 and $5 r_{\text {eff }}$, where $r_{\text {eff }}=3 /\left(\rho_{\text {ice SSA }}\right)$ is the effective radius. At $1310 \mathrm{~nm}$, the ice optical constant used was $n_{1310}=1.29584+i 1.302 \times 10^{-5}$, based on the compilation of Warren and Brandt (2008). The real part used is that of the compilation. For the imaginary part, the compilation value is $1.310 \times 10^{-5}$ at $-7^{\circ} \mathrm{C}$ but there is a $2 \%$ experimental uncertainty and an unquantified temperature dependence, so our value is reasonable. At $1550 \mathrm{~nm}$, the optical constant used was $n_{1550}=1.2907+i 4.586 \times 10^{-4}$. The real part is that of Warren and Brandt (2008). For the imaginary part, Gosse et al. (1995) recommend $4.26 \times 10^{-4}$ at $-22^{\circ} \mathrm{C}$, with an error of $3 \%$ and a temperature dependence of $0.6 \% \mathrm{~K}^{-1}$ (Warren and Brandt, 2008), so that our value is within the acceptable range. The effect of using modified optical constants is small. At $1310 \mathrm{~nm}$, under the conditions of our experimental setup, for snow with $\mathrm{SSA}=30 \mathrm{~m}^{2} \mathrm{~kg}^{-1}$ and density $=400 \mathrm{~kg} \mathrm{~m}^{-3}$, the modified constants change hemispherical reflectance from 0.4049 to 0.4059 . At $1550 \mathrm{~nm}$, for snow with SSA $=100 \mathrm{~m}^{2} \mathrm{~kg}^{-1}$ and density $=400 \mathrm{~kg} \mathrm{~m}^{-3}$, the modified constants change hemispherical reflectance from 0.1028 to 0.0960 . 
In our sphere, the illumination is mostly by direct light with normal incidence, but the snow is also illuminated by diffuse light coming from all over the sphere surface. Since hemispherical reflectance depends on the angle of incidence (and therefore on the diffuse/direct character of the illumination), modeling the reflectance measured by DUFFISSS requires the estimation of the amount of diffuse light hitting the snow. The photon distribution in an ideal integrating sphere evolves as a Markov process (Pickering et al., 1993). We adapted the simple yet accurate Markov model presented and evaluated in Hidović-Rowe et al. (2006) to our experimental geometry. The model needs to assume that the snow surface is flat and Lambertian, an approximation whose impact is delicate to evaluate. It also accounts for the optical baffle which blocks the detector from specular reflection (Fig. 2). Hidović-Rowe et al. (2006, their Sect. 2) show how to express the diffuse downwelling radiation $f_{d}^{\downarrow}$ as a fraction of the incident direct beam. Applying their recipe for $f_{d}^{\downarrow}$ to our detector configuration (flat sample with baffle occluding specular reflectance), we obtain:

$f_{d}^{\downarrow}=\frac{\dot{r} \omega \alpha s}{1-(s+d)-\omega \alpha\{1-[d+(1-r) s]\}}$

where $\dot{r}$ is the snow hemispherical reflectance to direct normal radiation, and $\omega$ and $r$ are the hemispherical reflectances of the sphere wall and the snow to isotropic illumination, respectively. The remaining parameters are the normalized surface areas of the photodiode $(d=0.000145)$, snow sample ( $s=0.015877)$, and laser diode $(h=0.002336)$. The reflective sphere wall area $(\alpha=0.981642)$ is determined by the normalization condition $\alpha+d+h+s=1$.

We observed, however, that the signal was higher than expected in the absence of a sample indicating that the beam collimation was not perfect and that some photons hit the sphere walls directly. Correcting Eq. (3) to account for emission fractions $\dot{f}$ and $1-\dot{f}$ initially striking the sample (collimated photons) and the sphere walls (stray photons), respectively, yields

$f_{d}^{\downarrow}=\omega s \frac{\dot{f} \dot{r} \alpha+\{1-\dot{f}\}[1-(s+d)]}{1-(s+d)-\omega \alpha\{1-[d+(1-r) s]\}}$

The theoretical signal, $m$, expected to be measured at the photodiode is :

$m=\omega d \frac{\dot{f} \dot{r} \alpha+\{1-\dot{f}\}[1-(s+d)]}{1-(s+d)-\omega \alpha\{1-[d+(1-r) s]\}}$

In practice, the gain of the electronics, $G$, and an offset, $A$, caused by electronic or optical noise has been added so that the actual signal $m_{\text {real }}$, is:

$m_{\text {real }}=G m+A$

Equation (6) was used to fit the calibration curves of Fig. 3. According to the manufacturer, reflectance standards are

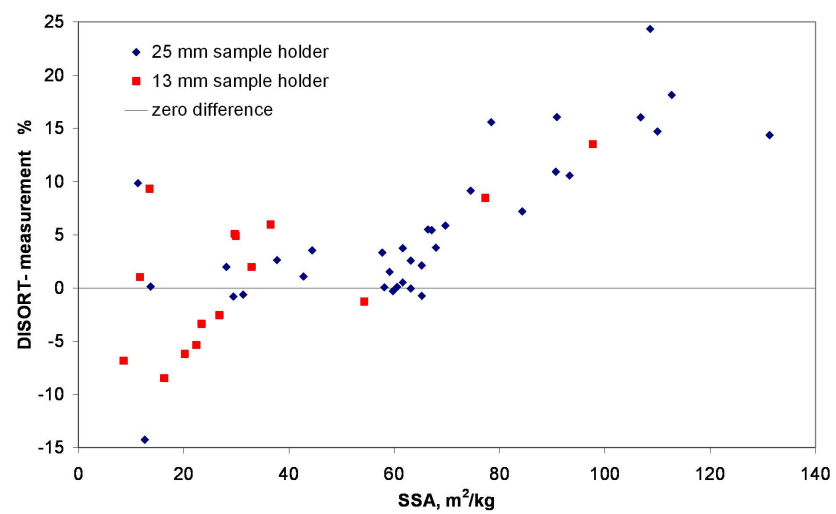

Fig. 7. Difference in reflectance at $1310 \mathrm{~nm}$, for given SSA values, between the calculations by DISORT and our measured value. DISORT uses snow with a density of $400 \mathrm{~kg} \mathrm{~m}^{-3}$. The systematically lower value of our measurement for SSA $>66 \mathrm{~m}^{2} \mathrm{~kg}^{-1}$ appears clearly. The lowest point on the graph, at SSA $=12.6 \mathrm{~m}^{2} \mathrm{~kg}^{-1}$, was a melt-freeze crust with a rough surface that affected the measurement quality.

lambertian so we use $\dot{r}=r$ in Eq. (5) for the standards. Fitting the curve yielded the values for $\omega, \dot{f}, G$ and $A$. We used two different integrating spheres and found $\omega_{1310}=0.972$ and $\omega_{1550}=0.965$ for the first one, and $\omega_{1310}=0.986$ and $\omega_{1550}=0.978$ for the other. The fitted calibration curves were then used to determine the reflectance of the snow samples from the photodiode signal.

Figure 5 also shows a SSA-Reflectance theoretical curve calculated for lighting conditions prevailing in the sphere, using DISORT to calculate $\dot{r}$ and $r$ and Eq. (4) to account for diffuse light reflected by the snow. We used a horizontally infinite $25 \mathrm{~mm}$-thick snow layer of density $400 \mathrm{~kg} \mathrm{~m}^{-3}$ (i.e. dense and deep enough to consider the medium semiinfinite), made of disconnected spheres. For this theoretical curve, done for our first sphere, we used $\omega_{1310}=0.972$ and $\dot{f}=0.95$. The value of $\dot{f}$ in fact has little impact on the calculated reflectance at $1310 \mathrm{~nm}$. For example, for $\mathrm{SSA}=40 \mathrm{~m}^{2} \mathrm{~kg}^{-1}$, reflectance is $46.081 \%$ for $\dot{f}=0.9$ and $45.807 \%$ for $\dot{f}=1$. However, the value of $\omega$ has a noticeable impact. Changing $\omega$ from 0.972 to 0.986 produced a relative increase in reflectance for a given SSA of about $5 \%$. The theoretical calibration to use therefore depends on the sphere and diode properties and has to be recalculated using DISORT for every system. Our combined SSA-reflectance measurements of Fig. 5 allowed the determination of the adequate optical parameters and size distribution to use.

Figure 7 shows quantitatively the difference between calculated and measured hemispherical reflectances, for the SSA values obtained by $\mathrm{CH}_{4}$ adsorption. For $\mathrm{SSA}<66 \mathrm{~m}^{2} \mathrm{~kg}^{-1}$, the data are reproduced fairly well. There is scatter of $\pm 10 \%$ for a number of points with SSA around $20 \mathrm{~m}^{2} \mathrm{~kg}^{-1}$. It is tempting to attribute this difference to grain shape as several theoretical studies show that it influences 


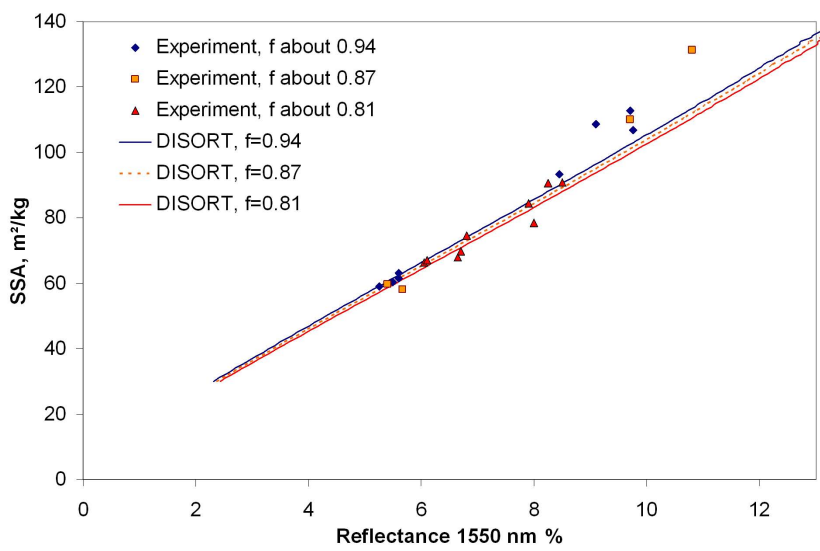

Fig. 8. Calibration curve to determine snow specific surface area from hemispherical reflectance at $1550 \mathrm{~nm}$ measured with DUFISSS. Specific surface area was measured by $\mathrm{CH}_{4}$ adsorption at $77 \mathrm{~K}$. Hemispherical reflectance was obtained with snow samples contained in a $25 \mathrm{~mm}$ deep sample holder. Hemispherical reflectance was also calculated using the DISORT model, for $25 \mathrm{~mm}$ thick snow samples of density $400 \mathrm{~kg} \mathrm{~m}^{-3}$, over a surface with $6 \%$ reflectance. Measurements and calculations were performed for 3 values of $\dot{f}$.

reflectance (Picard et al., 2009, and references therein). However, some of these points were obtained from samples with rounded grains, while others were from depth hoar, and for the moment we have not detected experimentally any correlation between grain shape and reflectance. These lowSSA samples all had large grains, and it was difficult to obtain a smooth sample surface. Some surfaces had hollows, while others had grains sticking out of the surface despite precautions taken to smooth the surface. Given the geometric artifact discussed above, it is clear that this affected reflectance, and we suggest that this uneven sample surface is the main reason for the difference between experiment and theory. In Fig. 7, a cluster of points with SSA around $60 \mathrm{~m}^{2} \mathrm{~kg}^{-1}$ shows excellent agreement between theory and experiment, because the grains were much smaller and it was easier to obtain a smooth surface.

For $\mathrm{SSA}>66 \mathrm{~m}^{2} \mathrm{~kg}^{-1}$, the calculated reflectance is systematically greater than the measured value, and the difference is about $16 \%$ for $\mathrm{SSA}>75 \mathrm{~m}^{2} \mathrm{~kg}^{-1}$. We made detailed investigations to test whether these differences could be explained by density or geometric artifacts (Fig. 6). We also adapted the SNOWRAT ray-tracing model of Picard et al. (2009) to the configuration of DUFISSS. These investigations are detailed in the appendix. The conclusion is that snow of high SSA always has a low density, with the result that the optical depth will rarely be sufficient to avoid artifacts. Corrections are in principle possible, but these cause large uncertainties. We were therefore led to the inescapable conclusion that our integration sphere with illumination at $1310 \mathrm{~nm}$ is not adapted to the measurement of the SSA of low-density high-SSA snow. For such snows, large optical depth can only be reached by using much deeper sample holder or by chosing a wavelength with a greater absorption than $1310 \mathrm{~nm}$. We propose a method based on this second option.

\section{Determination of high SSA values from hemispherical reflectance at $1550 \mathrm{~nm}$}

The ice absorption band around $1500 \mathrm{~nm}$ is stronger than that around $1300 \mathrm{~nm}$ and is a good candidate to avoid the density and geometric artifacts in low density snow. If however absorption is too large, the reflectance signal will be too low, reducing accuracy. Given commercially available laser diodes, the best compromise that we found was to use $1550 \mathrm{~nm}$ radiation.

Figure 8 shows the SSA-reflectance calibration data at $1550 \mathrm{~nm}$. As before, the reflectance at $1550 \mathrm{~nm}$ (and also at $1310 \mathrm{~nm}$ ) was measured, followed by a SSA measurement using $\mathrm{CH}_{4}$ adsorption at $77 \mathrm{~K}$, and by a second reflectance measurement. Only snow samples with high SSAs were selected for these measurements. These were necessarily fresh or very recent snow samples that therefore had low densities. Figure 8 also shows calculations using DISORT, without geometric corrections, using $\omega_{1550}=0.965$. At $1550 \mathrm{~nm}$, calculated reflectances were found to show a significant dependence on $\dot{f}$. This is probably because at $1550 \mathrm{~nm}$ snow hemispherical reflectance more strongly depends on the angle of incidence than at $1310 \mathrm{~nm}$. Figure 8 therefore shows three curves for the $\dot{f}$ values corresponding to those used in the experiments. For SSAs in the range $58-93 \mathrm{~m}^{2} \mathrm{~kg}^{-1}$, with densities in the range $35-178 \mathrm{~kg} \mathrm{~m}^{-3}$, our experimental points coincide well with the predictions of DISORT and in particular the data points obtained with $\dot{f}=0.81$ tend to show a higher reflectance than those obtained with $\dot{f}=0.94$. However, for the five samples whose SSAs fall in the range 107$131 \mathrm{~m}^{2} \mathrm{~kg}^{-1}$, with densities in the range $33-41 \mathrm{~kg} \mathrm{~m}^{-3}$, measured reflectances are slightly lower than calculated by DISORT.

It is essential to test whether these differences are simply due to experimental error or whether they are an artifact of the very low snow density even at $1550 \mathrm{~nm}$. Modeling tests using DISORT and SNOWRAT led to the conclusion that, with the available data, the deviation of the calibration points from theory at very high SSA, shown in Fig. 8, is not caused by an artifact. Details of the supporting calculations are reported in the appendix. We therefore conclude that it is due to experimental error. Indeed, random errors of 5 to $10 \%$ can explain the observed difference between calculations and measurements. Additional data points would be desirable, but opportunities to sample snow with such high SSAs are few. 


\section{Recommendations to determine SSA from hemispherical reflectance}

The above experimental and modeling data, including those in the appendix, indicate that snow SSA can be determined rapidly and accurately in the laboratory or in the field using DUFISSS and the following recommendations.

\subsection{Recommendation for snow with $\mathrm{SSA}<60 \mathrm{~m}^{2} \mathbf{k g}^{-1}$}

For snow with $\mathrm{SSA}<60 \mathrm{~m}^{2} \mathrm{~kg}^{-1}$, we recommend the use of $1310 \mathrm{~nm}$ radiation. The first step is to determine the signalto-reflectance relationship as in Fig. 3. This curve is used to determine the reflectance of the sphere wall $\omega$, the diode collimation $\dot{f}$, and the gain $G$ and offset $A$ defined in Eq. (6). To determine these four parameters, we recommend the use of at least six standards. We emphasize the importance of using one high-reflectance standard to obtain a robust determination of the parameters.

The next step is to use the reflectance-to-SSA relationship calculated using DISORT, Eqs. (4) to (5), the optical parameters and the size distribution given in section 3.1. The DISORT curve of Fig. 5, can be used for $\omega=0.972, \dot{f}$ between 0.9 and 1 , and for snow densities $\rho>200 \mathrm{~kg} \mathrm{~m}^{-3}$. To facilitate the use of Fig. 5, we propose the following polynomial fit, with SSA in $\mathrm{m}^{2} \mathrm{~kg}^{-1}$ and hemispherical reflectance $R_{S}$ in $\%$ :

$$
\begin{aligned}
& S S A=1.739 \times 10^{-7} R_{s}^{5}-1.633 \times 10^{-5} R_{s}^{4}+8.166 \times \\
& 10^{-4} R_{s}^{3}-0.01081 R_{s}^{2}+0.4508 R_{s}+0.03519
\end{aligned}
$$

Even though we recommend Eq. (7) for SSA $<60 \mathrm{~m}^{2} \mathrm{~kg}^{-1}$, we are fairly confident that it can be used in the range $1<\mathrm{SSA}<66 \mathrm{~m}^{2} \mathrm{~kg}^{-1}$, as suggested by Fig. 5 . For the same SSA range, but for $50<\rho<200 \mathrm{~kg} \mathrm{~m}^{-3}$, we recommend taking into account the effect of density, $\rho$. To derive an empirical equation that takes into account density, we used SNOWRAT simulations detailed in the appendix. From those data, we propose to replace the measured reflectance $R_{s}$ with a corrected value $R_{s, \text { corr }}$ :

$$
R_{s, \mathrm{corr}}=\frac{R_{s}\left(2000+0.986 \rho^{2.25}\right)}{\rho^{2.25}}
$$

and to use $R_{s, \text { corr }}$ in Eq. (7) to obtain the SSA. Equation (8) has no theoretical basis, it is purely empirical and its only merit and purpose are to reproduce our data and calculations. Many other forms of equations could be proposed, all with the same arbitrary character.

The error on SSA can be evaluated. The reflectance standards have an absolute accuracy of $0.6 \%$, determined by the manufacturer. An individual SSA measurement using $\mathrm{CH}_{4}$ adsorption has a random error of $6 \%$ (Legagneux et al., 2002). The relevant part of the calibration curve in Fig. 3 uses 34 points, and we estimate that the error done by using this calibration is $4 \%$. The random error of one reflectance measurement is $1 \%$, as detailed in Sect. 2. Despite the fact that we could not detect any significant effect of snow crystal shape on reflectance, there is a clear possibility that this effect does exist, and we estimate that it may produce an error of $3 \%$ on SSA. The use of Eqs. (7) and (8) produce an error which is less than $1 \%$ in all cases. At $1310 \mathrm{~nm}$, the error caused by variations in $\dot{f}$ is considered negligible, if $\dot{f}$ remains between 0.9 and 1 . The total random error in SSA determination is therefore $8 \%$. This estimate may seem optimistic in view of Fig. 7. However, a lot of the outlying points were obtained at an early stage of our work, before we had fully realized the impact of the state of the sample surface on reflectance, especially for samples with large grains. Subsequent measurements averaged a larger number of samples, reducing the random error.

The main systematic error is that of the $\mathrm{CH}_{4}$ adsorption method. Legagneux et al. (2002) estimated it at $10 \%$, leading to an overall error of $12 \%$. However, Kerbrat et al. (2008) showed that the $\mathrm{CH}_{4}$ adsorption method gave results within $3 \%$ of X-ray tomography, so that it is reasonable to suggest that the systematic error due to $\mathrm{CH}_{4}$ adsorption is $5 \%$ or less. In that case, combining a random error of $8 \%$ and a systematic error of $5 \%$, we conclude that the uncertainty of SSA determination using IR hemispherical reflectance at $1310 \mathrm{~nm}$ under the current conditions is $10 \%$.

As discussed in Sect. 3.1, SSA determination is also affected by the value of $\omega$, the reflectance of the sphere wall. For a given sphere, the determination of $\omega$ by curve fittings is sufficiently accurate that we neglect uncertainties on $\omega$. However, different spheres have different $\omega$ values, which needs to be taken into account when calculating the adequate calibration curve. Sensitivity studies using DISORT indicate that, as a rule of thumb, using a value of $\omega$ that is too low by 0.003 will cause the SSA to be overestimated by $1 \%$. For our second sphere, we calculated using DISORT the theoretical curve for $\omega=0.986$ and $\dot{f}=0.85$. Both factors contribute to a greater fraction of diffuse light $f_{d}^{\downarrow}$, as dictated by Eq. (4) so that the measured reflectance of snow samples increased. The new equation was:

$$
\begin{aligned}
& \mathrm{SSA}=2.959 \times 10^{-7} R_{s}^{5}-3.789 \times 10^{-5} R_{s}^{4}+2.229 \times \\
& 10^{-3} R_{s}^{3}-0.05498 R_{s}^{2}+1.073 R_{s}-3.412
\end{aligned}
$$

And the SSA values obtained are about $6 \%$ lower than if Eq. (7) were used. Therefore, large changes in sphere properties, if uncorrected, only lead to moderate changes in SSA so that the method can be considered robust.

\subsection{Recommendation for snow with $\mathrm{SSA}>60 \mathrm{~m}^{2} \mathrm{~kg}^{-1}$}

For snow with $\mathrm{SSA}>60 \mathrm{~m}^{2} \mathrm{~kg}^{-1}$, we recommend the use of $1550 \mathrm{~nm}$ radiation and the DISORT curves of Fig. 8, which 
shows that the beam collimation that determines $\dot{f}$ noticeably affects the location of the curve. We recommend to collimate the beam to obtain about an $8 \mathrm{~mm}$ spot on the snow in order to illuminate a representative surface. With our $1550 \mathrm{~nm}$ Mitsubishi laser diode, $\dot{f}$ is then close to 0.87 . To facilitate the use of Fig. 8, we propose the following polynomial fit, valid for $50<\mathrm{SSA}<160 \mathrm{~m}^{2} \mathrm{~kg}^{-1}$, with SSA in $\mathrm{m}^{2} \mathrm{~kg}^{-1}$ and $R_{S}$ in \%:

$\mathrm{SSA}=0.07637 R_{s}^{2}+8.480 R_{s}+11.55$

The error on this determination can be evaluated as above. Assuming that $\dot{f}=0.87$, the error in the calibration curve is here estimated to be $5 \%$ because of the lower number of data points than at $1310 \mathrm{~nm}$. The random error due to reflectance measurement is $2 \%$, and the error due to crystal shape is again $3 \%$, leading to a random error of $10 \%$. Using an estimate of systematic error of 5\%, we evaluate the accuracy of SSA measurement using reflectance at $1550 \mathrm{~nm}$ to be $12 \%$.

For the sake of completeness, we mention here the polynomial fit when $\dot{f}=0.94$ :

$\mathrm{SSA}=0.07320 R_{s}^{2}+8.636 R_{s}+11.78$

and for $\dot{f}=0.81$ :

$\mathrm{SSA}=0.07923 R_{s}^{2}+8.335 R_{s}+11.34$

Implicitly, the $60 \mathrm{~m}^{2} \mathrm{~kg}^{-1}$ threshold suggests that the SSA of the snow must be evaluated before the measurement is made. This requirement is somewhat relaxed because both ranges overlap over the $50-66 \mathrm{~m}^{2} \mathrm{~kg}^{-1}$ range. Moreover, in practice, a moderate amount of training and experience by a careful observer is sufficient to allow the visual estimation of SSA within about $20 \%$. This was tested a number of times by writing down field estimates, subsequently compared to measurements.

\section{Determination of snow SSA in the field using DUFISSS}

We have used DUFISSS many times in Alpine, Arctic and Antarctic environments. DUFISSS can easily be used to measure the SSA of surface snow, and to obtain the vertical SSA profile of a snow cover. In general, once the stratigraphy has been observed and the instrument is in place, the SSA values of 10 to 20 layers can be measured in less than $30 \mathrm{~min}$ by two people. One person samples the snow as shown in Fig. 4, weighs the filled sample holder to measure the snow density, and hands it over to the other person who measures reflectance. Meanwhile, the first person fills a second identical sample holder.

Such measurements allow the determination of the snow area index (SAI) of snowpacks. The SAI has been defined by Taillandier et al. (2006), by analogy to the leaf area index
(LAI) as the vertically integrated surface area of the snowpack. It is expressed in $\mathrm{m}^{2}$ of snow surface area per $\mathrm{m}^{2}$ of ground, and is therefore a dimensionless variable. It is computed as:

$\mathrm{SAI}_{\text {snowpack }}=\sum_{i} \mathrm{SSA}_{i} h_{i} \rho_{i}$

with $h$ the height of layer $i$ and $\rho_{i}$ its density. Layers thicknesses are obtained from stratigraphic observations, density is obtained from the sample preparation and SSA is obtained with DUFISSS.

\section{Conclusions}

DUFISSS allows the rapid determination of snow SSA in the field with an accuracy better than $12 \%$. The principle, technology and use of DUFISSS are simple, making it a useful tool for chemical, climate, and snow physics research. As stated in the introduction, it can be used to study atmospheresnow exchanges of chemicals (Burniston et al., 2007), especially right after snow falls, when SSA decreases rapidly. Hopefully it can also be used to help relate changes in snow radiative properties to snow physical properties, in particular in remote sensing studies. This may not be simple, however, because radiative properties measured in the field or derived from satellites are usually directional, not hemispherical, and complex BRDF considerations may be necessary. New approaches however appear promising (Zege et al., 2008). Finally, this rapid method will be beneficial for the study of snow physics, and in particular the understanding of the factors affecting the rate of SSA changes, because in the past this has been limited by the small amount of data that could be obtained by $\mathrm{CH}_{4}$ adsorption (Taillandier et al., 2007).

This method complements those of Matzl and Schneebeli (2006) and of Painter et al. (2007a). Both those methods are excellent to obtain the detailed stratigraphy of snowpacks, while our method is not designed for that useful purpose. On the other hand, and as detailed in the introduction, DUFISSS operates at longer wavelengths than both these previous methods, and as shown in Fig. 1, more accurate SSA determinations can in principle be obtained, especially for high SSA snows. In summary, an ideal snow stratigraphic study will use the high resolution stratigraphic imaging proposed by those other authors, and the SSA measurement method proposed here.

\section{Appendix A}

The comparison between experimental hemispherical reflectance data and modeling using DISORT at $1310 \mathrm{~nm}$ is detailed in Sect. 3 and in Fig. 5. A good agreement is observed for snows with $\mathrm{SSA}<66 \mathrm{~m}^{2} \mathrm{~kg}^{-1}$, but deviations are observed for snows with higher SSAs. In particular, if SSA $>75 \mathrm{~m}^{2} \mathrm{~kg}^{-1}$, deviations up to $24 \%$ are observed. This 
Table A1. Hemispherical reflectances at $1310 \mathrm{~nm}$ of experimental snow samples with high SSA and low density, compared to calculations using DISORT that test the effect of density, and to calculations that account for the geometric artifact. $\dot{f}=0.95$ was used in all the calculations.

\begin{tabular}{|c|c|c|c|c|c|c|}
\hline $\begin{array}{l}\text { Measured SSA, } \\
\mathrm{m}^{2} \mathrm{~kg}^{-1}\end{array}$ & $\begin{array}{l}\text { Measured } \\
\text { density } \\
\mathrm{kg} \mathrm{m}^{-3}\end{array}$ & $\begin{array}{l}\text { Sample holder } \\
\text { depth, mm }\end{array}$ & $\begin{array}{l}\text { Measured } \\
\text { reflectance, } \\
\%\end{array}$ & $\begin{array}{l}\text { Calculated } \\
\text { reflectance } \\
\% \text {, actual } \\
\text { density }\end{array}$ & $\begin{array}{l}\text { Calculated } \\
\text { reflectance } \% \text {, } \\
\text { density }=400 \\
\mathrm{~kg} \mathrm{~m}^{-3}\end{array}$ & $\begin{array}{l}\text { Reflectance } \\
\text { with actual } \\
\text { density and } \\
\text { geometric } \\
\text { artifact, \% }\end{array}$ \\
\hline 131.3 & 35 & 25 & 52.2 & 65.21 & 66.05 & 60.89 \\
\hline 112.7 & 36 & 25 & 53.1 & 62.60 & 63.69 & 58.08 \\
\hline 108.6 & 35 & 25 & 49.5 & 61.89 & 63.23 & 57.16 \\
\hline 97.7 & 109 & 13 & 53.7 & 61.26 & 61.48 & 59.57 \\
\hline 77.3 & 169 & 13 & 53.0 & 57.64 & 57.68 & 55.30 \\
\hline
\end{tabular}

appendix reports the tests that were made to identify the causes of this disagreement and the attempts to correct for them.

\section{A1 Modeling using DISORT at $1310 \mathrm{~nm}$}

To test whether the finite optical depth of the sample owing to the low density of some samples could explain the gap between our theoretical curve and the data for $\mathrm{SSA}>75 \mathrm{~m}^{2} \mathrm{~kg}^{-1}$ we calculated with DISORT the hemispherical reflectance of these $25 \mathrm{~mm}$ deep samples 1) using their measured densities and 2) using a density of $400 \mathrm{~kg} \mathrm{~m}^{-3}$, large enough to ensure that no significant radiation reached the bottom of the sample. Table A1 compares the experimental data to calculations. Comparison of both calculated values for each sample show that the reflectance with actual density is no more than $1 \%$ lower than that of a semi-inifinite medium. This shows that the gap between the experimental points with $\mathrm{SSA}>75 \mathrm{~m}^{2} \mathrm{~kg}^{-1}$ and the theoretical curve of Fig. 5 cannot be explained by the density artifact alone.

To assess the contribution of the geometric artifact to the measured reflectance $R_{S}$, we modeled $R_{S}$ as the sum (over all snow layers) of the product of two independent terms for each layer: the mean field-of-view (FOV, measured in hemispheres) subtended, and the reflectance contribution $R_{k}$ predicted by plane-parallel radiative transfer theory. We approximated the geometric correction due to finite horizontal and vertical sample dimensions as Eq. (A1), the sum of layerdependent geometric factors $\left(\mathrm{FOV}_{k}\right)$ times the corresponding plane-parallel layer reflectance contribution $\left(A_{k}\right)$. These factors are intuitive and predictable for all wavelengths with standard methods.

$R_{s}=\sum_{k} \mathrm{FOV}_{k} R_{K}$

The snow was discretized on a 32-layer vertical grid stretching in layer thicknesses from $10 \mu \mathrm{m}$ near the top to $2.5 \mathrm{~mm}$ near the bottom. On this grid, no layer contributes more than $10 \%$ to $R_{s}$. For each layer, we calculated the mean solid angle of the integrating sphere subtended by each snow layer. Snow farther from the central axis of the sample container subtends a smaller planar angle $\psi$ of the aperture (Fig. 6b), and occupies a greater relative surface area than snow nearer the central axis. The average layer FOV is estimated as the surface-area mean FOV of all snow extending out to the radius of illumination. Note that the FOV determined in this way is geometric only; it does not account for attenuation and scattering. The FOV of diffusely illuminated snow decreases from 1.0 to 0.43 to 0.2 hemispheres ( 1 hemisphere is a solid angle of $2 \pi$ steradian) as snow depth increases from 0 to 13 to $25 \mathrm{~mm}$. The FOV depends on whether the beam is collimated or whether illumination is diffuse. At $25 \mathrm{~mm}$ depth, the mean FOV for snow illuminated by the collimated beam ( $\sim 10 \mathrm{~mm}$ diameter) exceeds that of snow diffusely illuminated across the entire aperture by about $6 \%$.

The plane-parallel prediction of each layer's contribution to reflectance $R_{k}$ was constructed by applying the adding method to the delta-Eddington approximation of snow sample optical properties. After first discretizing the (presumably) homogeneous snow sample into 32 layers, the procedure of Coakley et al. (1983) was used to determine and add the optical properties for each layer. We treat the sample holder bottom as an additional layer with reflectance $6 \%$ and transmittance $0 \%$ in order to determine its contribution to reflectance. At $1310 \mathrm{~nm}$, the measured snow reflectance in the $13 \mathrm{~mm}$ sample holder is within about $2.5 \%$ of the reflectance of a semi-infinite layer, $A_{\infty}$, of bright snow of low density $\left(50 \mathrm{~kg} \mathrm{~m}^{-3}, \mathrm{SSA}=100 \mathrm{~m}^{2} \mathrm{~kg}^{-1}\right)$. For the $25 \mathrm{~mm}$ sample holder, or for fresh snow of higher density $\left(>100 \mathrm{~kg} \mathrm{~m}^{-3}\right)$, $R_{s}$ deviates from $R_{\infty}$ by $<0.1 \%$. We estimate that the absorbing lower boundary reduces the measured reflectance of the samples in Table A 1 by less than $1 \%$ from their semiinfinite value. The geometric correction (Eq. A1) results in relative reduction of the plane-parallel modeled reflectance Rs for the samples shown in Table A1 by $6.6 \%, 7.2 \%, 7.6 \%$, 

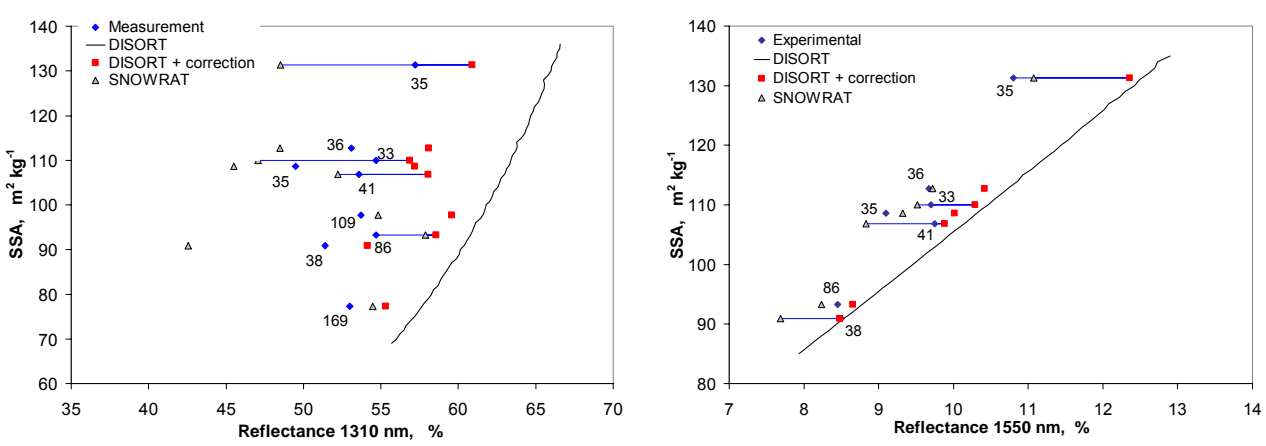

Fig. A1. Hemispherical reflectance at $1310 \mathrm{~nm}$ (left) and $1550 \mathrm{~nm}$ (right) of snow samples whose SSA was measured using $\mathrm{CH}_{4}$ adsorption at $77 \mathrm{~K}$. Three methods were used to obtain hemispherical reflectance: measurement with the integration sphere, calculation using DISORT with geometric corrections using Eq. (A1), and the ray-tracing model SNOWRAT. For each snow sample, there are therefore 3 reflectance values, some of which are connected by blue lines for clarity. The numbers next to each measured value is the mean density of the snow sample in the sample holder, in $\mathrm{kg} \mathrm{m}^{-3}$. (Left) The SSA-Reflectance relationship using DISORT without correction, for snow of density $400 \mathrm{~kg} \mathrm{~m}^{-3}$ and with $\dot{f}=0.95$, is also shown. (Right) The SSA-Reflectance relationship using DISORT without correction, with $\dot{f}=0.94$, is also shown.

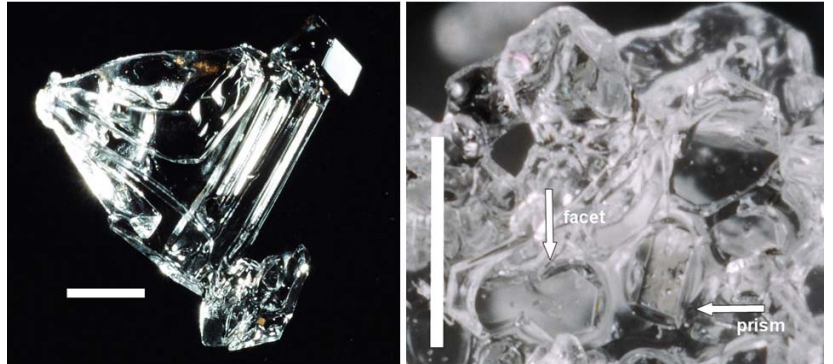

Fig. A2. Left: depth hoar crystal, showing the coexistence of faceted and rounded shapes. Right: melt-freeze crust, showing faceted shapes, even though melt-freeze crusts are often thought to consist only of rounded shapes. Scale bars: $1 \mathrm{~mm}$.

$2.8 \%$, and $4.1 \%$, respectively. Hence this geometric correction reduces the bias between the measured and planeparallel modeled reflectances in Table A1 by $25-50 \%$. At the same time, the geometric correction reduces $R_{S}$ by less than $\sim 1 \%$ for denser snow $\left(>200 \mathrm{~kg} \mathrm{~m}^{-3}\right)$ with moderately high SSA $\left(\sim 66 \mathrm{~m}^{2} \mathrm{~kg}^{-1}\right)$.

Figure A1a shows that for those low-density samples with SSA $>66 \mathrm{~m}^{2} \mathrm{~kg}^{-1}$, these corrections only account for less than half of the difference between the reflectance values measured and those calculated by DISORT for a $25 \mathrm{~mm}$-thick snow layer of density $400 \mathrm{~kg} \mathrm{~m}^{-3}$. We believe that this is because our corrections and DISORT cannot take into account the complex path taken by rays of light in the sample. Our correction method hypothesizes that if a given areal fraction of a given snow layer is illuminated, the fraction of scattered light that will escape the sample can be predicted by simple geometric considerations. However, the three-dimensional sample geometry causes edge effects that are not captured by the one-dimensional multiple scattering algorithm (DISORT) or by our geometric corrections. We conclude that planeparallel optical models, even with corrections, are inadequate for quantitative treatment of bright, low-density snow reflectance in DUFISSS.

\section{A2 Modeling using a ray-tracing model at $1310 \mathrm{~nm}$}

The other approach pursued was to use the ray-tracing method of Picard et al. (2009) to obtain theoretical calibration curves for various snow densities. Picard et al. (2009) showed that snow hemispherical reflectance was highly dependent on crystal shape. For example, for a given SSA, the reflectance of cubes was $27 \%$ greater than that of disconnected spheres, as used in DISORT. However, for SSAs lower than $66 \mathrm{~m}^{2} \mathrm{~kg}^{-1}$, this large dependence is not reproduced by our data, which do not show much scatter around the DISORT theoretical curve, calculated using disconnected spheres (Fig. 5). We suggest that this is due to the fact that natural snow always contains a mixture of a wide range of shapes. Indeed, except perhaps for surface hoar, snow is never formed of only faceted crystals. This is because faceted shapes are caused by rapid growth, which is fed by the sublimation of other crystals, and sublimation always produces rounded shapes (Nelson, 1998). Figure A2 shows a depth hoar crystal, with the obvious and typical coexistence of both faceted and rounded shapes. Likewise, snow is rarely if ever formed of only rounded shapes. Melt-freeze crusts are generally thought to consist only of rounded shapes. However, Fig. A2 also shows a melt-freeze crust, and although rounded shapes predominate, faceted forms are commonly found. We speculate that these could be formed either in localized environments where latent heat release produced large water vapor fluxes or because these melt-freeze crusts were subjected to strong transient temperature gradients that produced rapid growth after the melting event. Snow subjected to perfectly 

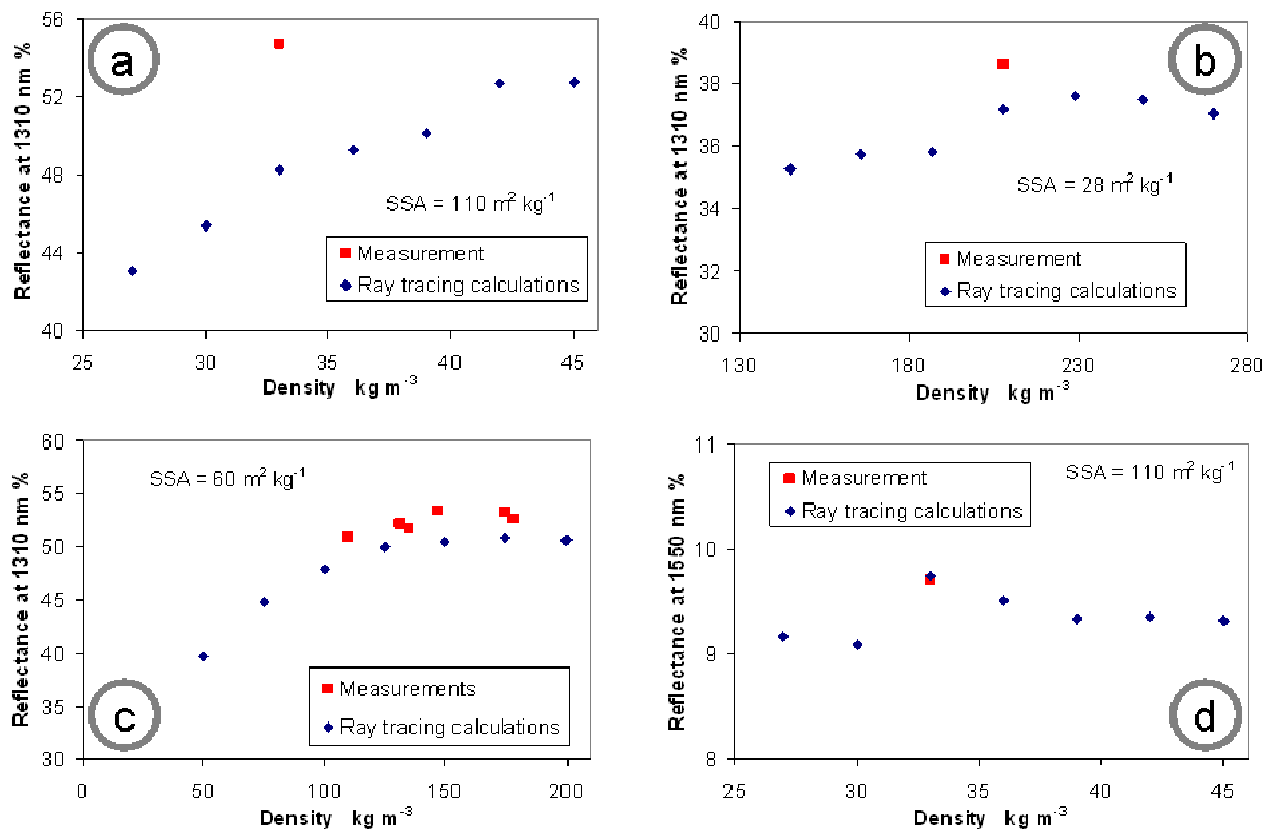

Fig. A3. Effect of snow density on hemispherical reflectance as calculated by SNOWRAT for our integration sphere. (a) With illlumination at $1310 \mathrm{~nm}$ for low-density snows of SSA $=110 \mathrm{~m}^{2} \mathrm{~kg}^{-1}$. The measured hemispherical reflectance of a snow sample of the same SSA is also shown. (b) At $1310 \mathrm{~nm}$, for snows of moderate densities and of SSA=28 $\mathrm{m}^{2} \mathrm{~kg}^{-1}$. The measured hemispherical reflectance of a snow sample of SSA $=28.1 \mathrm{~m}^{2} \mathrm{~kg}^{-1}$ is also shown. (c) At $1310 \mathrm{~nm}$ for snows of low to moderate densities and with $\mathrm{SSA}=60 \mathrm{~m}^{2} \mathrm{~kg}^{-1}$. The measured hemispherical reflectances of snow samples having SSAs in the range $57-63 \mathrm{~m}^{2} \mathrm{~kg}^{-1}$ are also shown. (d) At $1550 \mathrm{~nm}$ for lowdensity snows of $S S A=110 \mathrm{~m}^{2} \mathrm{~kg}^{-1}$. The measured hemispherical reflectance of a snow sample of the same SSA is also shown. In all four panels, SNOWRAT simulates the snow with disconnected spheres. The curves are not perfectly smooth because of numerical noise.

isothermal conditions is also commonly thought to consist only of rounded shapes (Colbeck, 1983). However, using scanning electron microscopy, Domine et al. (2003) showed that even in such snow, facets were formed. In summary, we suggest that natural snow is almost always made of a variety of shapes that will considerably reduce the dependence of hemispherical reflectance on snow crystal shape as discussed by Picard et al. (2009).

We therefore applied a modified version of the ray-tracing model of Picard et al. (2009), SNOWRAT, to which we added a representation of the integrating sphere and computed the reflectance of the snow samples having the SSA values shown in Fig. A1a, treating the snow as disconnected spheres. SNOWRAT does not treat stray photons, so that $\dot{f}=1$. This can produce a systematic bias in the data, but so can the arbitrary selection of spheres as crystal shape. We therefore need to remain aware of such a possible systematic bias when interpreting SNOWRAT results, which have been added to Fig. A1a. While the geometric correction always undercorrected DISORT reflectances, Fig. A1a shows that the differences between measured and SNOWRAT values at first sight appear random. A closer look shows that SNOWRAT underestimates reflectance for snow of very low density $\left(33-41 \mathrm{~kg} \mathrm{~m}^{-3}\right)$ and overestimates reflectance for snow of low density $\left(86-109 \mathrm{~kg} \mathrm{~m}^{-3}\right)$.
The impact of density on ray-tracing-derived reflectances was therefore tested. Figure A3a shows calculations of the reflectances of $25 \mathrm{~mm}$ deep snow samples of $\mathrm{SSA}=110 \mathrm{~m}^{2} \mathrm{~kg}^{-1}$ of various densities. The measured reflectance of a snow sample with the same SSA is also shown. As density is increased from 27 to $45 \mathrm{~kg} \mathrm{~m}^{-3}$, the reflectance increases dramatically, from 43 to almost $53 \%$. This demonstrates that in our system, the measured reflectance is extremely sensitive to density for low density values i.e. when the optical depth is small. We believe that this may explain the differences between measured and ray-tracing-derived reflectances in Figs. A1a and A3a. Experimentally, the density of our samples are measured simply by weighing the sample holder filled with snow and this of course only measures the mean density in the sample holder. For reflectance measurements, the sample holder is scraped after being filled with snow, to obtain a flat level surface. This may affect the density of the surface layer, which is then different from the mean density. Figure A1a suggests that when the density if very low, our sample handling increases the density of the surface layer, while the opposite is observed when the density is somewhat higher. Figure A3a also plots a measured value, whose reflectance is about $6.5 \%$ higher than calculations. This is consistent with calculations that show that reflectance measured by DUFISSS is highly sensitive to 
density (for low densities) and with our suggestion that the mean density may not reflect density variations within the sample, so that predicting reflectance from the mean density may result in errors.

Figure A3b shows a plot of the effect of density on the reflectance of low SSA $\left(28 \mathrm{~m}^{2} \mathrm{~kg}^{-1}\right)$ snow samples. Such snows are usually denser than high-SSA snows, and the density range chosen here is $145-270 \mathrm{~kg} \mathrm{~m}^{-3}$. Figure A3b shows that over this range, reflectance only varies between 35.25 and $37.60 \%$, and these extreme values include numerical noise, i.e. noise caused by an insufficient number of light rays used (1 million) because of limitations in computer ressources, which results in imperfect convergence. Therefore, actual meaningful variations in calculated reflectance are probably within $1 \%$. The measured reflectance of a snow sample with SSA $=28.1 \mathrm{~m}^{2} \mathrm{~kg}^{-1}$ is also shown, and is $38.9 \%$, within $1.5 \%$ of the calculated value. The facts that at moderate SSA and density, reflectance weakly depends on density and that calculated and measured reflectances are close indicate that determining SSA from reflectance measured in a $25 \mathrm{~mm}$ deep sample holder is possible for such snows. However, the data of Fig. A3a lead to the conclusion that, given the density dependence of reflectance for snow of low density and high SSA, and given the fact that fresh snow of high SSA almost always has a low density, our integration sphere with illumination at $1310 \mathrm{~nm}$ is not well adapted to the measurement of the SSA of low-density high-SSA snow.

Given the artifact detected in low-density high-SSA snow, it is legitimate to wonder whether such an artefact might also be observed in snows of moderate SSAs and moderate densities, because in that case the optical depth may also be insufficient. This may for example be the case for fresh snow that has aged in the absence of wind, and whose SSA would have decreased below $60 \mathrm{~m}^{2} \mathrm{~kg}^{-1}$, while its density would have remained below $100 \mathrm{~kg} \mathrm{~m}^{-3}$. To test for that, additional SNOWRAT calculations performed for SSA $=60 \mathrm{~m}^{2}$ $\mathrm{kg}-1$ are shown in Fig. A3c. They show that as long as density is greater than $100 \mathrm{~kg} \mathrm{~m}^{-3}$, any correction for density is small. However, for densities between 50 and $100 \mathrm{~kg} \mathrm{~m}^{-3}$, corrections are more important. Figure A3b and c were used to propose empirical Eq. (8) in the main text, that can be used when the snow density is between 50 and $200 \mathrm{~kg} \mathrm{~m}^{-3}$.

For snows of yet lower densities, which are always fresh and therefore of high SSA, corrections would be too large and probably cause a significant error. This is why we tested whether using the wavelength of $1550 \mathrm{~nm}$, where ice absorption is larger than at $1310 \mathrm{~nm}$, increases sufficiently the optical depth without changing the sample holder physical depth.

\section{A3 Modeling using a ray-tracing model at $1550 \mathrm{~nm}$}

Figure A3d shows the effect of density on reflectance at $1550 \mathrm{~nm}$, as calculated by the ray-tracing model with the DUFISSS geometry. The variations appear to be within nu- merical noise, and the density and geometric artifacts can therefore be neglected at $1550 \mathrm{~nm}$.

To confirm this, the second panel of Fig. A1 compares measured reflectances to those calculated using SNOWRAT, DISORT, and DISORT with the geometric correction. The differences between the measurements and SNOWRAT predictions are between $0.01 \%$ and $0.53 \%$ of reflectance in absolute value and are random, consistent with the absence of a detectable density artifact. The geometric correction is too small to explain the systematically too bright DISORT bias. Although we realize that the number of data points available at very high SSA is limited, we conclude with available data that the deviation of the calibration points from theory at very high SSA, shown in Fig. 8, is due to experimental error and not to an effect of density.

Acknowledgements. DUFISSS was built without any external funds, despite repeated requests. We thank the LGGE director for his encouragements and support. Ray-tracing calculations were made on the OSUG cluster maintained by F. Roch at Université Joseph Fourier, Grenoble. We thank Laurent Arnaud, Eric Lefebvre and Jean-Philippe Balestrieri for useful advice on some aspects of the instrumentation. CSZ was supported by NSF ARC-0714088 and NASA NNX07AR23G and acknowledges partial support from CNRS during his sabbatical year at LGGE. We are grateful to T. Painter, M. Schneebeli, and an anonymous reviewer for their helpful comments. We thank S. Gruber for detailed editing of the manuscript.

Edited by: S. Gruber

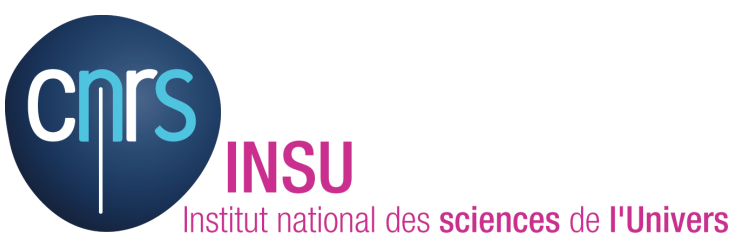

The publication of this article is financed by CNRS-INSU.

\section{References}

Aoki, T., Aoki, T., Fukabori, M., Hachikubo, A., Tachibana, Y., and Nishio, F.: Effects of snow physical parameters on spectral albedo and bidirectional reflectance of snow surface, J. Geophys. Res., 105D, 10219-10236, 2000.

Beine, H. J., Honrath, R. E., Dominé, F., Simpson, W. R., and Fuentes, J. D.: $\mathrm{NO}_{\mathrm{x}}$ During Background and Ozone Depletion Periods at Alert: Fluxes Above the Snow Surface, J. Geophys. Res., 107(D21), 4584, doi:10.1029/2002JD002082, 2002.

Burniston, D. A., Strachan, W. J. M., Hoff, J. T., and Wania, F.: Changes in surface area and concentrations of semivolatile organic contaminants in aging snow, Environ. Sci. Technol., 41, 4932-4937, 2007.

Cabanes, A., Legagneux, L., and Dominé, F.: Evolution of the specific surface area and of crystal morphology of Arctic fresh snow during the ALERT 2000 campaign, Atmos. Environ., 36, 27672777, 2002. 
Cabanes, A., Legagneux, L., and Dominé, F.: Rate of evolution of the specific surface area of surface snow layers, Environ. Sci. Technol., 37, 661-666, 2003

Coakley, J. A, Cess, R. D., and Yurevich, F. B.: The effect of tropospheric aerosols on the Earth's radiation budget: a parameterization for climate models, J. Atmos. Sci., 40, 116-138, 1983.

Colbeck, S. C.: Ice crystal morphology and growth rates at low supersaturations and high temperatures, J. Appl. Phys., 54, $2677-$ 2682, 1983.

Coléou, C., Lesaffre, B., Brzoska, J.-B., Ludwig, W., and Boller, E.: Three-dimensional snow images by X-ray microtomography, Ann. Glaciol., 32, 75-81, 2001.

Daly, G. L. and Wania, F.: Simulating the influence of snow on the fate of organic compounds, Environ. Sci. Technol., 38, 41764186, 2004.

Davis, R. E., Dozier, J., and Perla, R.: Measurement of snow grain properties. In : Seasonal Snowcovers: Physics, Chemistry, Hydrology, edited by: Jones, H. G. and Orville-Thomas, W. J., D. Reidel Publishing Dompany, 63-74, 1987.

Dominé, F. and Shepson, P. B.: Air-snow interactions and atmospheric chemistry, Science, 297, 1506-1510, 2002.

Dominé, F., Lauzier, T., Cabanes, A., Legagneux, L., Kuhs, W. F., Techmer, K., and Heinrichs, T.: Snow metamorphism as revealed by scanning electron microscopy, Microsc. Res. Tech., 62, 3348, 2003.

Domine, F., Salvatori, R., Legagneux, L., Salzano, R., Fily, M., and Casacchia, R.: Correlation between the specific surface area and the short wave infrared: SWIR reflectance of snow, Cold Regions Sci. Technol., 46, 60-68, 2006.

Domine, F., Taillandier, A.-S., and Simpson, W. R.: A parameterization of the specific surface area of snow in models of snowpack evolution, based on 345 measurements, J. Geophys. Res., 112, F02031, doi:10.1029/2006JF000512, 2007a.

Domine, F., Cincinelli, A., Bonnaud, E., Martellini, T., and Picaud, S.: Adsorption of Phenanthrene on Natural Snow, Environ. Sci. Technol., 41, 6033-6038, 2007b.

Domine, F., Albert, M., Huthwelker, T., Jacobi, H.-W., Kokhanovsky, A., Lehning, M., Picard, G., and Simpson, W. R.: Snow Physics as Relevant to Snow Photochemistry, Atmos. Chem. Phys., 8, 171-208, 2008, http://www.atmos-chem-phys.net/8/171/2008/.

Flanner, M. G. and Zender, C. S.: Linking snowpack microphysics and albedo evolution, J. Geophys. Res., 111, D12208, doi:10.1029/2005JD006834, 2006.

Flanner, M. G., Zender, C. S., Randerson, J. T., Rasch, P. J.: Present-day climate forcing and response from black carbon in snow, J. Geophys. Res., 112, D11202, doi:10.1029/2006JD008003, 2007.

Flin, F., Brzoska, J.-B., Lesaffre, B., Coléou, C., and Pieritz, R. A.: Full three-dimensional modelling of curvature-dependent snow metamorphism: first results and comparison with experimental tomographic data, J. Phys. D. Appl.Phys., 36, 1-6, 2003.

Gosse, S., Labrie, D., and Chylek, P.: Refractive index of ice in the 1.4-7.8- $\mu \mathrm{m}$ spectral range, Appl. Optics, 34, 6582-6586, 1995.

Gow, A. J.: On the rates of growth of grains and crystals in south polar firn, J. Glaciol., 8, 241-252,1969.

Grannas, A. M., Jones, A. E., Dibb, J., Ammann, M., Anastasio, C., Beine, H. J., Bergin, M., Bottenheim, J., Boxe, C. S., Carver, G., Chen, G., Crawford, J. H., Dominé, F., Frey, M. M., Guzmán,
M. I., Heard, D. E., Helmig, D., Hoffmann, M. R., Honrath, R. E., Huey, L. G., Hutterli, M., Jacobi, H. W., Klán, P., Lefer, B., McConnell, J., Plane, J., Sander, R., Savarino, J., Shepson, P. B., Simpson, W. R., Sodeau, J. R., von Glasow, R., Weller, R., Wolff, E. W., and Zhu, T.: An overview of snow photochemistry: evidence, mechanisms and impacts, Atmos. Chem. Phys., 7, 4329-4373, 2007, http://www.atmos-chem-phys.net/7/4329/2007/.

Grenfell, T. C., Warren, S. G., and Mullen, P. C.: Reflection of solar radiation by the Antarctic snow surface at ultraviolet, visible, and near-infrared wavelengths, J. Geophys. Res., 99, 18669-18684, 1994.

Grenfell, T. C. and Warren, S. G.: Representation of a nonspherical ice particle by a collection of independent spheres for scattering and absorption of radiation, J. Geophys. Res., 104, $31697-$ 31709, 1999.

Hall, A.: The role of surface albedo feedback in climate, J. Climate, 17, 1550-1568, 2004.

Herbert, B. M. J., Halsall, C. J., Villa, S., Jones, K. C., and Kallenborn, R.: Rapid changes in PCB an OC pesticide concentrations in Arctic snow, Environ. Sci. Technol., 39, 2998-3005, 2005.

Hidović-Rowe, D., Rowe, J. E., and Lualdi, M.: Markov models of integrating spheres for hyperspectral imaging, Appl. Optics, 45, 5248-5257, 2006.

Honrath, R. E., Peterson, M. C., Guo, S., Dibb, J. E., Shepson, P. B., and Campbell, B.: Evidence of $\mathrm{NO}_{\mathrm{x}}$ production within or upon ice particles in the Greenland snowpack, Geophys. Res. Lett., 26, 695-698, 1999.

Jacobi, H.-W. and Hilker, B.: A mechanism for the photochemical transformation of nitrate in snow, J. Photochem. Photobiol. A., 185, 371-382, 2007.

Jones, A. E., Weller, R., Anderson, P. S., Jacobi, H.-W., Wolff, E. W., Schrems, O., and Miller, H.: Measurements of $\mathrm{NO}_{\mathrm{x}}$ emissions from the Antarctic snowpack, Geophys. Res. Lett., 28, 1499-1502, 2001.

Kaempfer T. U. and Schneebeli, M.: Observation of isothermal metamorphism of new snow and interpretation as a sintering process, J. Geophys. Res., 112, D24101, doi:10.1029/2007JD009047, 2008.

Kerbrat, M., Pinzer, B., Huthwelker, T., Gäggeler, H. W., Ammann, M., and Schneebeli, M.: Measuring the specific surface area of snow with X-ray tomography and gas adsorption: comparison and implications for surface smoothness, Atmos. Chem. Phys., 8, 1261-1275, 2008, http://www.atmos-chem-phys.net/8/1261/2008/.

Kokhanovsky, A. A.: Scaling constant and its determination from simultaneous measurements of light reflection and methane adsorption by snow samples, Opt. Lett., 31, 3282-3284, 2006.

Legagneux, L., Cabanes, A., and Dominé, F.: Measurement of the Specific Surface Area of 176 Snow Samples Using Methane Adsorption at 77 K, J. Geophys. Res., 107(D17), 4335 , doi:10.1029/2001JD001016, 2002.

Matzl, M. and Schneebeli, M.: Measuring specific surface area of snow by near-infrared photography, J. Glaciol., 52, 558-564, 2006.

Narita, H.: Specific surface of deposited snow II, Low Temp. Sci., A29, 69-81, 1971.

Nolin, A. W. and Dozier, J.: A hyperspectral method for remotely sensing the grain size of snow, Remote Sens. Environ., 74, 207 
216, 2000.

Nelson, J.: Sublimation of ice crystals, J. Atmos. Sci., 55, 910-919, 1998.

Painter, T. H., Molotch, N. P., Cassidy, M., Flanner, M., and Steffen, K.: Contact Spectroscopy for Determination of Stratigraphy of Optical Grain Siz, J. Glaciol., 53, 121-127, 2007a.

Painter T. H., Barrett, A. P., Landry, C. C., Neff, J. C., Cassidy, M. P., Lawrence, C. R., McBride, K. E., and Farmer G. L.: Impact of disturbed desert soils on duration of mountain snow cover, Geophys. Res. Lett., 34, L12502, doi:10.1029/2007GL030284, 2007b.

Perla, R., Dozier, J., and Davis, R. E.: Preparation of serial sections in dry snow specimens, J. Microsc., 141, 111-114, 1986.

Picard, G., Arnaud, L., Domine, F., and Fily, M.: Determining snow specific surface area from near-infrared reflectance measurements: numerical study of the influence of grain shape, Cold Regions Sci. Technol., 56(1), 10-17, 2009.

Pickering, J. W., Prahl, S. A., Vanwieringen, N., Beek, J. F., Sterenborg, H. J. C. M., and Vangemert, M. J. C.: Double-integratingsphere system for measuring the optical properties of tissue, Appl. Optics, 32, 399-410, 1993.

Schaepman-Strub, G., Schaepman, M. E., Painter, T. H., Dangel, S., and Martonchik, J. V.: Reflectance quantities in optical remote sensing-definitions and case studies, Remote Sens. Environ., 103, 27-42, 2006.

Stamnes, K., Tsay, S. C., Wiscombe, W., and Jayaweera, K.: Numerically stable algorithm for discrete-ordinate-method radiative transfer in multiple scattering and emitting layered media, Appl. Optics, 27, 2502-2509, 1988.
Taillandier, A.-S., Domine, F., Simpson, W. R., Sturm, M., Douglas, T. A., and Severin, K.: Evolution of the Snow Area Index of the subarctic snowpack in Central Alaska over a whole season. Consequences for the air to snow transfer of pollutants, Environ. Sci. Technol., 40, 7521-7527, 2006.

Taillandier, A.-S., Domine, F., Simpson, W. R., Sturm, M., and Douglas, T. A.: The rate of decrease of the specific surface area of dry snow: isothermal versus temperature gradient conditions, J. Geophys. Res., 112, F03003, doi:10.1029/2006JF000514, 2007.

Warren, S. G.: Optical properties of snow, Rev. Geophys. Space Phys., 20, 67-89, 1982.

Warren, S. G.: Optical constants of ice from the ultraviolet to the microwave, Appl. Optics, 23, 1206-1225, 1984.

Warren S. G. and Brandt, R. E.: Optical constants of ice from the ultraviolet to the microwave: A revised compilation, J. Geophys. Res., 113, D14220, doi:10.1029/2007JD009744, 2008.

Wiscombe, W. J. and Warren, S. G.: A model for the spectral albedo of snow, I: Pure snow. J. Atmos. Sci., 37, 2712-2733, 1980.

Zege, E., Katsev, I., Malinka, A., Prikhach, A., Polonsky, I.: New algorithm to retrieve the effective snow grain size and pollution amount from satellite data, Ann. Glaciol., 49, 139-144, 2008.

Zender, C. S. and Talamantes, J.: Solar absorption by Mie resonances in cloud droplets, J. Quant. Spectrosc. Radiat. Transfer, 98, 122-129, 2006. 